\title{
Xiphinema americanum Cobb, 1913 (Dorylaimida: Longidoridae): espécie-praga quarentenária para o Brasil.
}

\author{
Xiphinema americanum Cobb, 1913 (Dorylaimida: Longidoridae): quarantine \\ pest for Brazil. \\ Giovani Greigh de Brito $^{1}$ Ervandil Corrêa Costa ${ }^{2}$ Zaida Inês Antoniolli ${ }^{3}$ \\ Felipe Dörr ${ }^{4}$ Heleno Maziero ${ }^{5}$
}

- REVISÃO BIBLIOGRÁFICA -

RESUMO

\begin{abstract}
Diversos aspectos referentes à espécie-praga quarentenária Xiphinema americanum, incluindo características taxonômicas, distribuição geográfica, plantas hospedeiras, aspectos bioecológicos, potencial de transmissão de viroses e medidas de controle, entre outros, foram abordados nesta revisão. A dificuldade encontrada pelos especialistas na correta identificação deste nematóide quarentenário muitas vezes determina que $\boldsymbol{X}$. americanum seja confundido com outras espécies pertencentes ao mesmo gênero. Esta praga, além de utilizar como hospedeiras várias espécies de plantas e encontrar-se estabelecida em diversas regiões do globo terrestre, constitui-se em um agente transmissor de viroses, dentre as quais algumas são também consideradas quarentenárias para vários países, incluindo o Brasil. Considerando a sua ampla distribuição geográfica somada ao seu alto potencial de transmissão de viroses, o conhecimento dos aspectos abordados nesta revisão pode auxiliar na redução do risco de introdução deste nematóide quarentenário á áreas indenes no Brasil.
\end{abstract}

Palavras-chave: nematóides, transmissão de viroses, Xiphinema americanum.

\begin{abstract}
Different aspects concerning the quarantine pest $\boldsymbol{X}$. americanum, including taxonomic characteristics, world distribution, host plants, viruses transmission potential, control methods and others, were reviewed. The difficulty in correctly identifying this nematode usually results in its misleading into another species belonging to the same genus. Considering that this pest has almost a worldwide distribution and that it is a virus's vector, knowledge about it is important to avoid its introduction in new areas, like Brazil.
\end{abstract}

Key words: nematodes, nepovirus, Xiphinema americanum.

\section{INTRODUÇÃO}

A soberania agrícola de um país deve ser mantida por medidas fitossanitárias compatíveis com as novas tendências do mercado internacional, que não discriminem commodities domésticas e importadas, que não imponham barreiras alfandegárias sem a devida justificativa técnica e que ainda regulem a entrada de material vegetal capaz de portar pragas exóticas.

\footnotetext{
${ }^{1}$ Engenheiro Agrônomo, Aluno do Programa de Pós-graduação em Agronomia, Centro de Ciências Rurais (CCR), Universidade Federal de Santa Maria (UFSM), Departamento de Defesa Fitossanitária, Sala 3225, 2o andar. Fone: (55) 99619052. Email: gbrito@mail.ufsm.br. Autor para correspondência.

${ }^{2}$ Engenheiro Agrônomo, Doutor, Professor Titular, Departamento de Defesa Fitossanitária, CCR, UFSM.

${ }^{3}$ Biologo, Doutor, Professora Adjunta, Departamento de Solos, Prédio 42, Sala 3310, CCR, UFSM. E-mail: zaida@ccr.ufsm.br

${ }^{4}$ Mestrando em Bioquímica Toxicológica, UFSM.

${ }^{5}$ Engenheiro Agrônomo, Departamento de Defesa Fitossanitária, CCR, UFSM.
} 
A introdução de novas pragas, em áreas isentas das mesmas, pode ocasionar sérios problemas à agricultura de um país. Visando reduzir os riscos desta introdução, medidas quarentenárias devem ser adotadas. Dentre estas medidas, a relação de pragas quarentenárias para um país surge como referência básica.

No Brasil, o trabalho desenvolvido pelo Serviço de Quarentena Vegetal, órgão vinculado ao Ministério da Agricultura, Pecuária e Abastecimento, é de fundamental importância. Este órgão divulga as espécies realmente nocivas que se encontram próximas às fronteiras para que os riscos de sua introdução sejam minimizados. Através do conhecimento da praga, tem-se maior segurança na sua detecção no momento de inspeção do material vegetal.

A introdução do $\boldsymbol{X}$. americanum (LAMBERTI \& BLEVE-ZACHEO, 1979) semelhante a outras espécies-praga como o nematóide de cisto da soja (Heterodera glycines Ichinohe, 1952) (LORDELLO et al., 1992) e o bicudo do algodoeiro (Anthonomus grandis Boheman, 1843) (BARBOSA et al., 1983), poderá causar enormes prejuízos à agricultura nacional, incluindo redução da produtividade, aumento nos custos de produção e impacto ao meio ambiente pela utilização intensiva de agrotóxicos para seu controle.

Apesar de tratar-se de uma espécie que possui pouca mobilidade em função de suas características intrínsecas, este nematóide apresenta alguns aspectos que merecem ser considerados. Os meios de disseminação podem ser as próprias mudas infestadas com ovos, formas jovens ou adultas. Os instrumentos utilizados no preparo do solo, além do próprio homem, podem constituir-se em veículos de disseminação da praga (WARD \& HOCKLAND, 1996).

Assim, o objetivo da elaboração deste material é caracterizar a existência desta praga exótica - relatar sua distribuição geográfica atual, seus aspectos bioecológicos, potencial de transmissão de viroses e os métodos de controle adotados, entre outros, destacando a importância de se evitar o trânsito de material de origem vegetal que possa transportar este nematóide.

\section{POSIÇÃO SISTEMÁTICA}

Nome científico: Xiphinema americanum COBB, 1913. Sinonímias: Tylencholaimus americanus (COBB, 1913); Xiphinema taylori (LAMBERTI et al., 1991); Xiphinema californicum (LAMBERTI et al., 1988). Ordem: Dorylaimida: Família: Longidoridae

\section{DISTRIBUIÇÃO GEOGRÁFICA}

X. americanum encontra-se amplamente distribuído no Canadá e Estados Unidos e nas últimas décadas tem sido reportado em diversos outros países, incluindo regiões pertencentes a European Plant Protection Organization (EPPO) (EPPO, 2001).

Resultados de estudos evidenciam que, na América do Norte, $\boldsymbol{X}$. americanum apresenta-se atualmente estabelecido na região oriental do continente, e é comumente encontrado em áreas sob pastagens. Nessa região, foram identificadas vinte e cinco espécies, das quais dez foram consideradas novas para os pesquisadores. Entretanto, faz-se necessário considerar que muitos registros de ocorrência desta praga são duvidosos, tendo em vista que $\boldsymbol{X}$. americanum pode estar, em algumas regiões, sendo confundido com outras espécies pertencentes ao mesmo gênero (LAMBERTI et al., 1988). Na região delimitada pela EPPO, vários registros de $\boldsymbol{X}$. americanum referem-se, certamente, a outras espécies do mesmo gênero, incluindo $\boldsymbol{X}$. brevicolle e $\boldsymbol{X}$. pachtaicum, entre outras (LAMBERTI et al., 1988). Os registros encontrados revelam que $\boldsymbol{X}$. americanum encontra-se, atualmente, estabelecido nos seguintes países: Europa: Hungria, Polônia, Federação Russa, Espanha e Reino Unido (EPPO, 2001); Ásia: China, India, Japão, Paquistão, Filipinas e Turquia (EPPO, 2001); África: Nigéria (EPPO, 2001); Continente Americano: Argentina, Canadá, Chile, Equador, Guatemala, México, Panamá e Estados Unidos (EPPO, 2001); Oceania: Austrália (HARRIS, 1980).

\section{PLANTAS HOSPEDEIRAS DE $\boldsymbol{X}$. americanum COBB, 1913}

As principais plantas hospedeiras desta praga pertencem às seguintes espécies botânicas:

Avena sativa L. (aveia branca), Cichorium intybus L. (chicória), Citrus sinensis L. (laranja doce), Cocos nucifera L. (palmeira de coco), Codiaeum variegatum L. (cróton), Coffea arabica e $\boldsymbol{C}$. canephora L. (cafeeiro), Cucurbita pepo L. (abobrinha), Cynodon dactylon L. (grama seda) Fragaria ananassa Duchesne (morangueiro), Glycine max L. (soja), Gossypium hirsutum L. (algodoeiro), Juglans regia L. (nogueira), Linum usitatissimum L. (linho), Lycopersicon esculentum Mill. (tomateiro), Malus domestica Mill. (macieira), Malus sylvestris Mill (macieira silvestre), Mangifera indica L. (mangueira), Nicotiana tabacum L. (tabaco), Oryza sativa L. (arroz), Pennisetum clandestinum Hochst. (capim kikuio), Petunia hybrida L. (petúnia),. Pinus banksiana 
(pinus), Prunus armeniaca L. (damasco), Prunus avium L. (cerejeira), Prunus domestica L. (ameixeira), Prunus dulcis Mill. (amendoeira), Prunus persica L. (pessegueiro), Psidium guajava L. (goiabeira), Saccharum officinarum L. (cana-de-açúcar), Solanum tuberosum L. (batata), Sorghum vulgare L. (sorgo), Trifolium pratense L. (trevo vermelho) Vaccinium corymbosum L. (mirtilo), Vitis vinifera L. (parreira), Zea mays L. (milho), Zoysia japonica L. (grama japonesa), (GRIFFIN \& EPSTEIN, 1964; SIDDIQI, 1973; OLIVEIRA\& PAULA, 2000).

\section{ASPECTOS BIOECOLÓGICOS}

$\boldsymbol{X}$. americanum é de ocorrência freqüente em solos arenosos, localizando-se à profundidade média de $30 \mathrm{~cm}$ no perfil do solo. É geralmente encontrado na rizosfera de plantas hospedeiras dentre as quais se incluem o morangueiro, a cerejeira e a pereira (EPPO, 2001).

O comprimento das fêmeas adultas varia de 1,60 a 1,71mm e o dos machos está entre 1,50 e 1,70mm. A reprodução não requer a participação do macho, pois esta ocorre através da partenogênese, o que explica as ocorrências pouco expressivas de machos nas populações estudadas (BROWN et al., 1994).

O aparelho reprodutor da fêmea de $\boldsymbol{X}$. americanum difere em vários aspectos se comparado às demais espécies pertencentes ao mesmo gênero. $\mathrm{O}$ ovário possui uma estrutura ramificada envolvida por uma camada de células epiteliais, sob as quais estão presentes bactérias simbióticas. Possui ovidutos longos e dilatados em determinados pontos. O esfíncter situado entre o oviduto e o útero possui lúmen sinuoso, composto por tecidos musculares internos. O útero é extremamente curto, o que é considerado um traço evolutivo marcante para esta espécie-praga (COOMANS \& CLAEYS, 1998).

$X$. americanum passa por três estágios durante seu ciclo evolutivo até atingir a fase adulta. No entanto, a ocorrência de quatro estágios juvenis é comumente observada (BROWN et al., 1994). Segundo este pesquisador, esta espécie requer no mínimo um ano para completar o seu ciclo de vida. Embora seja um ectoparasita, possui órgão especializado (estilete) que lhe permite romper os tecidos das raízes, destruindo as paredes da célula vegetal e causando severos danos à planta atacada.

As condições edafoclimáticas ótimas para o seu desenvolvimento e reprodução são temperaturas ao redor de $22^{\circ} \mathrm{C}$, e umidade no solo no mínimo igual a $70 \%$ e no máximo 90\% capacidade de campo . O pH ótimo para o desenvolvimento de $\boldsymbol{X}$. americanum situa-se entre 6,0 e 6,6. Solos com altos teores de cloreto de sódio ou extremamente ácidos encurtam o tempo de sobrevivência desta praga, principalmente durante as fases jovens. Produtos como o nitrato de potássio, o sulfato de cobre, o cloreto de potássio, o cloreto de cálcio e os ácidos fórmico, butírico, propiônico e acético, são tóxicos para este nematóide (TACCONI \& AMBROGIONI, 1995).

\section{TRANSMISSÃO DE VIROSES}

Estudos têm comprovado a elevada capacidade de transmissão de viroses por $\boldsymbol{X}$. americanum. Na América do Norte, este nematóide é considerado um eficiente vetor de diversos nepovírus. Durante o processo de alimentação sobre plantas infectadas, esta praga extrai, através do estilete partículas virais presentes no citoplasma celular. Estas partículas são introduzidas no citoplasma celular de plantas sadias. Resultados de pesquisas revelam que o período decorrente entre o processo de aquisição de um vírus e a sua transmissão é de uma hora, em média (BITTERLIN \& GONSALVES, 1987).

Segundo BROWN et al. (1994), $\boldsymbol{X}$. americanum constitui-se em um eficiente transmissor de quatro espécies de nepovírus: Tomato ringspot nepovirus (ToRSV), Tobacco ringspot nepovirus (TRSV), Cherry rasp leaf nepovirus (CRLV) e Peach rosette mosaic nepovirus (PRLV). Apesar de permanecer apto a transmitir estas viroses por um período de até dois anos após a sua aquisição, a capacidade de transmissão decresce com o tempo de armazenamento das partículas virais no lúmen do esôfago do nematóide (MCGUIRE \& SCHNEIDER, 1973).

Em sob condições laboratoriais, populações de $\boldsymbol{X}$. americanum provenientes da rizosfera de macieira, comprovaram a transmissão de TORSV para o pepineiro (GRIESBACH \& MAGGENTI, 1989). No Estado da Pensilvânia, esta espécie-praga foi comprovada como transmissora de TORSV para Malus pumila (macieira), Prunus persica (pessegueiro), Vaccinium corymbosum (mirtilo) e Rubus idaeus (amoreira silvestre) (FORER \& STOUFFER, 1982). De acordo com os resultados obtidos por FORER \& STOUFFER (1982), X. americanum está comprovadamente relacionado à transmissão de Soybean stunt virus para plantas de soja. Considerando a alta capacidade de transmissão de viroses apresentada por $\boldsymbol{X}$. americanum, a sua significância fitossanitária para uma área indene é consideravelmente aumentada. 


\section{EXPRESSÃO ECONÔMICA E DETECÇÃO}

Nos Estados Unidos, os danos diretos causados pelo ataque de $\boldsymbol{X}$. americanum têm sido relatados em morangueiro, espécies frutíferas arbóreas, leguminosas forrageiras e essências florestais (MALEK, 1968; SIDDIQI, 1973). Este nematóide é considerado o principal responsável pelos baixos rendimentos obtidos por espécies frutíferas na Dakota do Sul (MALEK, 1968) e do trevo vermelho (Trifolium pratense) no Estado de Iowa (NORTON, 1967). Segundo RAMSDELL et al. (1996), no Estado de Michigan, parreirais com material híbrido FrenchAmerican tiveram seus rendimentos comprometidos devido ao ataque de quatro espécies de nematóides, incluindo $\boldsymbol{X}$. americanum. Quando comparadas com plantas saudáveis, plantas atacadas por esta praga apresentaram reduções médias de produtividade e crescimento de $40 \%$ e $60 \%$, respectivamente.

Outro aspecto importante a ser considerado diz respeito ao elevado custo da fumigação do solo que, associado à retirada do mercado de muitos produtos até então utilizados no processo, o tornou inviável. Isto determinou a busca, através da pesquisa, de alternativas a estes produtos. Atualmente, diversos cultivares de uva têm sido submetidos ao melhoramento genético visando à obtenção de características de resistência a esta praga (RAMSDELL et al., 1995).

Considerando a importância fitossanitária de $\boldsymbol{X}$. americanum, recomenda-se que o transporte de solo e de plantas contendo raízes, de qualquer país onde esta espécie encontra-se estabelecida, seja proibido (EPPO, 2001).

Informações relativas aos métodos de detecção e extração de nematóides do solo foram descritos por TACCONI \& AMBROGIONI (1995). Estes autores definiram que, em uma área equivalente a quatro hectares, devem ser amostrados 100 pontos, constituindo uma amostra estatisticamente representativa de $500 \mathrm{~g}$ de solo. A identificação deste nematóide deve ser precisa em relação a espécies e raças, devido à adoção de medidas quarentenárias e de controle desse parasita. Normalmente, a identificação é baseada na análise de caracteres morfológicos, através de microscópio ótico, de varredura ou de transmissão. Entretanto características fisiológicas, citogenéticas, sorológicas e moleculares podem estabelecer e mostrar diferenças entre espécies, raças ou mesmo populações morfologicamente semelhantes. Além disso, a identificação pode ser possível através de hospedeiros diferenciais, padrões enzimáticos, protéicos e através da análise direta do DNA (TENENTE \& LEALBERTIOLI, 1999; WANG et al., 2003).

\section{SINTOMAS}

Plantas atacadas por $\boldsymbol{X}$. americanum, na ausência de vírus, geralmente não exibem sintomas característicos na parte aérea. No entanto, sob alta densidade populacional observa-se redução do vigor da planta atacada, podendo ocorrer necrose e destruição das raízes de culturas suscetíveis, como por exemplo, a do morangueiro (GRIFFIN \& EPSTEIN, 1964).

Plântulas de Pinus banksiana atacadas apresentaram reduções do crescimento da parte aérea, enquanto reduções no crescimento de raízes foram observadas em Picea pungens. As plantas atacadas mostram-se mais suscetíveis às baixas temperaturas, se comparadas àquelas não parasitadas (GRIFFIN \& EPSTEIN, 1964).

Durante o processo de alimentação, nematóides infectados com alguma espécie de vírus realizam a transmissão do patógeno à planta hospedeira. Os sintomas das viroses são geralmente detectados na parte aérea durante a estação de crescimento da planta (BROWN et al., 1994).

\section{MEDIDAS DE CONTROLE}

As medidas a serem adotadas para pragas quarentenárias são: pré-colheita (prevenção ou redução da infestação inicial de pragas, produção em áreas livres de pragas quarentenárias), pós-colheita (tratamento térmico, imersão em água quente, irradiação e outros), pré-entrada (inspeção, quarentena de pós-entrada, exigências para a entrada da comoditie, certificação fitossanitária) e medidas pós-entrada (OLIVEIRA\& PAULA, 2000).

Controle químico

Métodos de controle foram revisados por SIDDIQI (1973) e OLIVEIRA.\& PAULA (2000). O tratamento de solo com nematicidas pode ser eficiente, controlando em até $95 \%$ estes organismos. Todavia, de acordo com esse autor, os nematóides que sobrevivem ao tratamento ainda podem transmitir vírus para as plantas saudáveis. O mesmo autor relata que o tratamento com nematicidas em pomares e parreirais reduz e estabiliza a população de $\boldsymbol{X}$. americanum durante algum tempo. Contudo, após dois anos em média, a praga pode voltar a causar danos expressivos devido aos espécimes que permanecem situados nas camadas profundas no perfil do solo.

Ciência Rural, v.35, n.1, jan-fev, 2005. 
Controle biológico

Objetivando encontrar alternativas ao controle químico, estudos relativos ao controle biológico de $\boldsymbol{X}$. americanum têm sido desenvolvidos. Os resultados obtidos têm se mostrado promissores.

Isolados do fungo Catenaria anguillulae apresentaram-se altamente virulentos para $\boldsymbol{X}$. americanum (JAFFEE \& SHAFFER, 1987). Biotestes relativos à utilização de isolados de bactérias no controle desta espécie-praga também foram efetuados. Elevadas taxas de parasitismo por Pseudomonas denitrificans têm sido verficadas sobre $\boldsymbol{X}$. americanum (BILGRAMI \& JAIRAPURI, 1989).

\section{Controle cultural}

Estudos relativos ao comportamento de $\boldsymbol{X}$. americanum frente ao manejo do solo têm sido efetuados. Práticas culturais, como a implantação de plantas de cobertura, não apresentam impactos imediatos sobre a dinâmica populacional da praga. Todavia, seus efeitos são evidenciados no tempo (HALBRENDT, 1995).

O potencial de uso de aleloquímicos de plantas tem sido constatado. A implantação, de forma intercalada, de espécies de plantas de cobertura, como Crotalaria spectabilis e Arachis hypogaea, foi capaz de reduzir a população de $\boldsymbol{X}$. americanum em pomares de frutíferas de clima temperado infestados (POLOZOV, 1979). No Chile, a utilização da leguminosa Lupinus albus como planta de cobertura em parreirais reduziu, de forma expressiva, a população de $\boldsymbol{X}$. americanum (ABALLAY et al., 2001).

Na Rússia, pesquisas efetuadas em fins da década de setenta relatam os efeitos de sessenta espécies de plantas sobre o desenvolvimento de $\boldsymbol{X}$. americanum. Os resultados mostram que, dentre as espécies estudadas, o trigo, o milheto, a aveia, a mostarda e a calêndula reduziram de forma significativa o desenvolvimento de $\boldsymbol{X}$. americanum. No entanto, Stellaria sp. e Chenopodium quinoa favoreceram o desenvolvimento desta espécie-praga (BOLDYREY \& BORZYKH, 1983).

Resultados interessantes têm sido obtidos através do emprego de rotação de culturas. A melhora da estrutura do solo favorece o desenvolvimento da planta de interesse agrícola em áreas infestadas e auxilia na diminuição da população de nematóides (HALBRENDT, 1995).

Resistência varietal

Os elevados custos do tratamento químico do solo com produtos fumigantes e a retirada de grande parte destes produtos do mercado, levou os pesquisadores a buscar outras alternativas para o controle de Xiphinema. A resistência varietal, principalmente para Peach rosette mosaic nepovirus (PRMV), transmitido por $\boldsymbol{X}$. americanum para a parreira, tem sido estudada e os resultados obtidos são promissores. A condução de um experimento por um período de quatro anos, no Estado de Michigan, em área com histórico da presença de $\boldsymbol{X}$. americanum e PRMV, demonstrou que o vírus foi detectado em menos de 5\% das parreiras da cultivar Chancellor e Couderc 1616, em 7\% das plantas das cultivares Couderc 1202 e Foch, e em 18,2\% das plantas das cultivares Niágara e Delaware (RAMSDELL et al., 1995). No entanto, segundo o mesmo autor, o vírus não foi detectado na cultivar Seyval durante todo o período em que o estudo foi conduzido, demonstrando, desta forma, a importância do desenvolvimento de cultivares resistentes no controle de Xiphinema. A resistência varietal surge como possibilidade de constituir-se em mais uma ferramenta a ser incluída no manejo integrado.

\section{CONCLUSÃO}

A elevada capacidade de transmissão de alguns nepovírus por $\boldsymbol{X}$. americanum, somada à dificuldade encontrada pelos taxonomistas na sua correta identificação, constituem-se em aspectos que aumentam, sobremaneira, a sua significância fitossanitária como praga quarentenária para um país. Destaca-se ainda sua ampla distribuição geográfica e número de espécies de plantas potencialmente hospedeiras. Considerando o dinâmico comércio entre as diversas partes do mundo, deve se obedecer às normas e exigências fitossanitárias de cada país de forma a reduzir a probabilidade de introdução e estabelecimento de pragas quarentenárias conforme a FAO (1996).

\section{REFERÊNCIAS BIBLIOGRÁFICAS}

ABALLAY, E. et al. Nematicidal effect of eight plant species on Xiphinema americanum sensu lato in Vitis vinifera, var. Cabernet Sauvignon in Chile. Nematropica, Santiago, v.31, n.1, p.95-102, 2001.

BARBOSA, S. et al. Relatório sobre a ocorrência do bicudodo-algodoeiro, Anthonomus grandis Boheman, "boll weevil', no Brasil e recomendações para sua erradicação. Campina Grande : EMBRAPA/CNPA, 1983. 20p. (Documentos, 21).

BILGRAMI, A.L.; JAIRAPURI, M.S. Resistance of prey to predation and strike rate of the predators Mononchoides longicaudatus M. fortidens (Nematoda: Diplogasterida). Revue de Nématologie, Aligarh, v.15, n.3, p.12-49, 1989. 
BITTERLIN, M.W.; GONSALVES, D. Spatial distribution of Xiphinema rivesi and persistence of tomato ringspot virus and its vector in soil. Plant Disease, v.71, n.5, p.408-411, 1987.

BOLDYREY, M.I.; BORZYKH, G.T. Plants in the control of nematodes. Zashchita Rastenii, Moscow, v.30, n.9, p.49-53, 1983.

BROWN, D.J.F. et al. Transmission of three North American nepoviruses by populations of four distinct species of the Xiphinema americanum group. Phytopathology, Invergowrie, UK, v.84, n.6, p.646-649, 1994.

COBB, N.A. New nematode genera found inhabiting fresh water and non-brackish soils. Journal of the Washington Academy of Sciences, Washington, v.36, n.4, p.432-444, 1913.

COOMANS, A.; CLAEYS, M. Structure of the female reproductive system of Xiphinema americanum (Nematoda: Longidoridae). Fundamental and Applied Nematology, Ledeganckstraat, Belgium, v.21, n.5, p.569-580, 1998

EUROPEAN PLANT PROTECTION ORGANIZATION EPPO. PQR database. Paris, France : Crop Protection Compendium, Cab International, 2001. 1CD-Rom.

FAO. Normas internacionales para medidas fitosanitarias: seccion 1 - Reglamentacion para la importacion: directrices para el analisis del riesgo de plagas. Roma, 1996. 21p. (FAO, Publicación, 2).

FORER, L.B.; STOUFFER, R.F. Xiphinema spp. associated with tomato ringspot virus infection of Pennsylvania fruit crops. Plant Disease, v.66, n.8, p.735-736, 1982.

GRIESBACH, J.A.; MAGGENTI, A.R. Vector capability of Xiphinema americanum sensu lato. California. Journal of Nematology, v.21, n.4 p.517-523, 1989.

GRIFFIN, G.D.; EPSTEIN, A.H. Association of dagger nematode, Xiphinema americanum, with stunting and winterkill of ornamental spruce. Phytopathology, Toronto, v.54, n.2, p.177-180, 1964.

HALBRENDT, J.M. Progress report: efficacy of crop rotation, green manure, and oxamyl as preplant nematode treatments. Fruit News, Pennsylvania, v.75, n.2, p.44-45, 1995.

HARRIS, A.R. Population studies of Xiphinema pachtaicum and $X$. americanum in a vineyard in north-eastern Victoria. Victoria : Mildura Horticultural Research Station, Department of Agriculture, 1980. 8p. (Research Project Series, n.75).

JAFFEE, B.A.; SHAFFER, R.L. Parasitism of Xiphinema americanum and $X$. rivesi by Catenaria anguillulae and other zoosporic fungi in soil solution, Baermann funnels, or soil. Nematologica, Louisiana. v.33, n.2, p.220-231, 1987.

LAMBERTI, F.; BLEVE-ZACHEO, T. Studies on Xiphinema americanum sensu lato with descriptions of fifteen new species (Nematoda, Longidoridae). Nematologia Mediterrânea, Bari, Italy, v.18, n.1, p.51-106, 1979.

LAMBERTI, F., da et al. On the identity of Xiphinema americanum in Chile with a key to the Xiphinema species occurring in Chile. Nematologia Mediterranea, Bari, Italy, v.16, n.3, p.67-77, 1988.

LAMBERTI, F., da et al. Relationship between Xiphinema brevicolle and $X$. diffusum with a redescription of $X$. brevicolle and descriptions of three new species of Xiphinema (Nematoda: Dorylaimida). Nematologia Mediterranea, Bari, Italy, v.19, n.5, p.311-326, 1991.

LORDELLO, A.I.L. et al. Occurrence of Heterodera glycines on soyabean in Brazil. Revista de Agricultura, Piracicaba, v.67, n.4, p.223-225, 1992.

MALEK, R.B. The dagger nematode, Xiphinema americanum, associated with decline of shelterbelt trees in South Dakota. Plant Disease, South Dakota, v.52, n.3, p.795-798, 1968.

MCGUIRE, J.M.; SCHNEIDER, I.R. Transmission of satellite of tobacco ringspot virus by Xiphinema americanum. Phytopathology, v.63, n.9, p.1429-1430, 1973.

NORTON, D.C. Xiphinema americanum as a factor in unthriftiness of red clover. Phytopathology, South Dakota, v.57, n.12, p.1390-1391, 1967.

OLIVEIRA, M.R.V.; PAULA, S.V. Propostas metodológicas para análise de risco de pragas quarentenárias de material vegetal. Brasília : Embrapa, Recursos Genéticos e Biotecnologia, 2000. 141p.

POLOZOV, V.M. Plant hosts of longidorid nematodes in the non-chernozem zone of the RSFSR (USSR). Sbornik Nauchnykh Rabot Nauchno-Issledovatel'skogo Zonal'nogo. Instituta Sadovodstva Nechernozemnoi Polosy (Plodovodstvo i yagodovodstvo nechernozemnoi polosy), Moscow, v.13, n.1, p.128-130, 1979.

RAMSDELL, D.C. da et al. Field pathogenicity studies of four species of plant-pathogenic nematodes on French-American hybrid grapevine cultivars in Michigan. Plant Disease, Michigan, v.11, n.2, p.334-338, 1996.

RAMSDELL, D.C., da et al. Susceptibility of American grapevine scion cultivars and French hybrid rootstock and scion cultivars to infection by peach rosette mosaic nepovirus. Plant Disease, Michigan, v.13, n.4, p.154-157, 1995.

SIDDIQI, M.R. Xiphinema americanum. CIH. Descriptions of plant-parastic nematodes. Wallingford, UK : CAB International, 1973. 4p. (Set, 29).

TACCONI, R.; AMBROGIONI, L. Xiphinema americanum Cobb sensu lato (Dorylaimida: Longidoridae), Nematodi da quarantena. Bologna, Italy. Lo Scarabeo, v.36, n.4, p.15-26, 1995.

TENENTE, R.C.V.; LEAL-BERTIOLI, S.C.M. Técnicas bioquímicas e moleculares na diagnose de fitonematóides. Brasília : Embrapa, Recursos Genéticos e Biotecnologia, 1999. 37p. (Boletim Técnico, 6).

WANG, X. et al. Multiplex polymerase chain reaction identification of single individuals of the longidorid nematodes Xiphinema index, X. diversicaudatum, $X$. vuittenezi, and $\boldsymbol{X}$. italiae using specific primers from ribosomal genes. Phytophatology, v.93, n.2, p.160-166, 2003.

WARD, M.G.; HOCKLAND, S. Nematodes and plant health: legislation and sampling strategies in decision making for nematode management. Pesticide Science, Texas, v.47, n.1, p.77-80, 1996. 